\title{
Development of the standard of quality of life in rural areas in the system of institutional building of the internal environment of the regional economy
}

\author{
Elena Ostapenko*
}

Stavropol State Agrarian University, 12, Zootechnicheskiy Lane, Stavropol, 355017, Russia

\begin{abstract}
Quality of life in rural areas as the main goal of rural development and regulation of this process by the state is the compliance of the standard of living of rural residents with state social standards in the sphere of material, social and cultural benefits provided to the population. In this regard, the standard of living in rural areas can be viewed through the prism of compliance with statistically measurable indicators reflecting the fulfillment of standards of living of rural residents. As a result of the analysis of existing approaches, the concept of sustainable development, which aims to improve the quality of life of the population, was chosen as the basic concept. To achieve the goal defined in the Concept of Sustainable Development, it is necessary to develop a Standard of Quality of Life, which would enshrine a set of necessary services for each rural resident, regardless of income, social status, health and age. The standard provides the functioning of the system of rules, creates a model of the quality of life in rural areas. The standard of the quality of life in rural areas should be considered as a system of minimum normative values, on the basis of which it is possible to make comparisons with other objects. The article proposes a methodology for the formation of a variable standard of quality of life in rural areas.
\end{abstract}

\section{Introduction}

The analysis of existing standards and methods of assessing the standard of living and quality of life allowed us to prepare a methodology for the formation of standards both for all territories in general and taking into account the unique characteristics of individual rural areas. This methodology for drafting the standard contains a direct method for calculating the indicators of the standard and regulatory and information base for their calculation.

\section{Problem Statement}

The standard includes indicators that reflect national development goals contained in national programs, as well as in the state program «Integrated Rural Development»: employment rate

*Corresponding author: helen_07-84@mail.ru 
of the rural population; employment rate of women with children of preschool age; unemployment rate of the rural population of working age; ratio of average monthly disposable resources of rural and urban households; share of total area of livable housing in rural settlements.

The systematization and analysis of existing approaches to the development of standards that determine the quality of life in the Russian Federation, including in rural areas, allowed to form a standard of quality of life in rural areas, the indicators of which reflect: the availability of services in the relevant area to each resident of rural areas; provision of the population with the necessary services; the quality of services provided to the population [1].

The generalizing element of each sphere of the standard is a matrix of minimum quantitative values of the standards of the quality of life in rural areas in the corresponding sphere. The matrix correlates: services; infrastructure facilities (specifies their availability, location in the relevant locality); accessibility of infrastructure (travel time to the facility, the radius of service, the distance from the facility to the consumer on public roads); availability of services (share of population receiving a service in the total population or in a particular category of population); quality of services (improvement of infrastructure, staffing); standard indicators; justified by orders, letters of line ministries, codes of practice, SNiPs, national standards of the Russian Federation, goals and objectives of state and departmental programs, national development goals of the Russian Federation.

In some cases, the results of statistical surveys and data from sociological surveys were used to substantiate the minimum quantitative values of indicators.

Taking into account the impossibility of applying universal standards, the need to take into account the unique features of rural areas in the areas of health care, trade and consumer services, education and road and transport communications was substantiated by experts.

With regard to the spheres of economy, communication infrastructure, social services, culture, environmental protection, public safety, physical culture, communal infrastructure, the need for compliance with the territorial and social equality of the quality of life standard has been established [2].

Developing a methodology for the formation of variable standards, statistically justified the allocation of the following groups of rural areas by population size:

- $\quad$ rural areas with the number of permanent residents from 51 to 300 people,

- $\quad$ rural areas with a permanent population of 301 to 650 people,

- $\quad$ rural areas with permanent residents from 651 to 1750 people,

- $\quad$ rural areas with a permanent population of 1,751 to 5,000 people,

- $\quad$ rural areas with 5001 to 10000 permanent residents,

- $\quad$ rural areas with permanent residents over 10,000 people.

The group of rural agglomerations was identified separately.

The distribution of rural areas into these groups was performed using SPSS Statistics.

The list of rural settlements on the territory of a constituent entity of the Russian Federation is determined by the supreme executive body of state authority of a constituent entity of the Russian Federation or by an executive body of a constituent entity of the Russian Federation authorized by the supreme executive body of state authority of a constituent entity of the Russian Federation. All changes territorial, administrative, municipal are recorded in the Handbook of territorial units of development of population data, which is maintained by the territorial bodies of Rosstat. The Handbook of Territorial Units for the Development of Population Data by Municipalities has existed since the 2000s and has been used as the main one since 2014. The codes of the directory are basically the same as the codes from the RNCMT.

Remote and hard-to-reach rural areas, for which varied standards of the quality of life can be developed are defined from the Order of the Ministry of Economic Development of the 
Russian Federation No 563 of 31.08.2020 «On approval of the list of relevant territories for the All-Russian population census of 2020».

In accordance with this normative act:

1) hard-to-reach settlements are recognized as settlements that:

(a) do not have a year-round connection by railroads, rivers, public roads of regional or intermunicipal importance of the subject of the Russian Federation and public roads of local importance:

- $\quad$ between the place of actual receipt of the goods and the locality;

- $\quad$ between the administrative center of the administrative-territorial unit and the settlement;

b) are not connected by public highways with paved roads to the network of public highways of federal, regional or intermunicipal importance and local importance located on the territory of the constituent entity of the Russian Federation;

c) are not provided with transportation links due to the lack of bridges and ferry crossings over water bodies that cross public highways of local importance;

2) small settlements are settlements with a population of less than 100 people;

3) remote settlements are those that simultaneously meet the following conditions:

a) the distance by motor roads from the boundary of a settlement to the boundary of the administrative center of a municipal district or urban district is more than ten kilometers;

b) the distance by motor roads from the boundary of the settlement to regional or federal highways is more than thirty kilometers.

According to this order the distribution of remote and hard-to-reach territories of the Russia into certain groups by population is presented in Table 1.

Table 1. Remote and hard-to-reach territories of the Russian Federation.

\begin{tabular}{|c|c|c|c|c|c|c|c|}
\hline \multirow{2}{*}{ Indicators } & \multicolumn{6}{|c|}{ Groups of areas by population } & Total \\
\cline { 2 - 8 } & $\begin{array}{c}\text { Up to 50 } \\
\text { people }\end{array}$ & $\begin{array}{c}51 \text { to } \\
300 \\
\text { people }\end{array}$ & $\begin{array}{c}301 \text { to } \\
650 \\
\text { people }\end{array}$ & $\begin{array}{c}651 \text { to } \\
1750 \\
\text { people }\end{array}$ & $\begin{array}{c}1750 \text { to } \\
5000 \\
\text { people }\end{array}$ & $\begin{array}{c}5001 \text { to } \\
10000 \\
\text { people }\end{array}$ & \\
\hline $\begin{array}{c}\text { Number of } \\
\text { rural } \\
\text { settlements }\end{array}$ & 23 & 184 & 237 & 259 & 83 & 13 & 799 \\
\hline $\begin{array}{c}\text { Population } \\
\text { size }\end{array}$ & 422 & 34396 & 113442 & 274821 & 227156 & 102900 & 753137 \\
\hline
\end{tabular}

The methodology for the formation of variable standards, taking into account the unique features of the territory in the field of education is shown in Table 2.

Indicators that take into account the unique characteristics of rural areas include:

1. Radius of emergency ambulance service for rural settlements with a population of up to 650 people not more than $20 \mathrm{~km}$. (not less than 1 ambulance team for the adult population, not less than 1 ambulance team for the child population).

2. Radius of service of emergency medical aid for rural localities with population over 651 persons not more than $10 \mathrm{~km}$ (not less than 1 emergency medical aid brigade per 10000 served adults, not less than 1 emergency medical aid brigade per 10000 served children population).

3. Service radius of mobile FAP for rural settlements with a population of up to 300 people not more than $30 \mathrm{~km}$.

4. Radius of accessibility of stationary FAP for rural settlements with a population of up to 650 people not more than $6.6 \mathrm{~km}$.

5. Average waiting time for emergency ambulance service for rural settlements with a population of up to 650 people not more than 45 minutes. 
6. Average waiting time for emergency ambulance services for rural settlements with a population of more than 651 people not more than 30 minutes.

7. Waiting time for pre-hospital medical care for rural localities with a population of up to 300 people not more than 60 minutes.

8. Transport accessibility for primary health care in stationary conditions for rural localities with less than 5000 inhabitants not more than $120 \mathrm{~min}$.

9. Radius of service of the trade organization is not more than $2 \mathrm{~km}$. (in difficult terrain, the radius of service should be reduced by $30 \%$ ).

10. The radius of service of the institution of consumer services is not more than $2 \mathrm{~km}$. (In a difficult terrain and in a zone of deserts and semi-deserts the service radiuses should be reduced by $30 \%)$.

11. Average travel time on public transport to the district center not more than 1,5 hours (in remote and inaccessible areas this standard may not be met).

12. Average travel time to the nearest federal highway not more than 90 minutes (in remote and inaccessible areas this standard may not be met).

13. 10. Average travel time to the nearest regional airport or airport of local airlines not more than 120 minutes (in remote and inaccessible areas this standard may not be met).

14. The radius of service of the educational institution is not more than $2 \mathrm{~km}$. (in conditions of difficult terrain the radius of service should be reduced by $30 \%$ ).

15. The radius of accessibility of the educational institution for settlements with a population of not more than 50 people is not more than $6.3 \mathrm{~km}$.

16. Average travel time for students to an educational institution of pre-school education for settlements with a population of not more than 300 people located outside the territory of the settlement not more than 30 minutes.

17. Average travel time for students to educational institutions for population of no more than 50 people located outside the territory of the settlement not more than 30 minutes.

18. Average travel time for students to educational institutions of primary and secondary vocational education for settlements with a population of not more than 5000 people located outside the territory of the settlement not more than 30 minutes.

The average travel time for students to an educational institution providing other educational services for settlements with a population of no more than 5000 people located outside the territory of the settlement is no more than 30 minutes [3,4].

Table 2. Indicators of the standard of quality of life in rural areas in the field of education (part).

\begin{tabular}{|c|c|c|c|c|}
\hline Indicator & Units & $\begin{array}{l}\text { The } \\
\text { standard }\end{array}$ & $\begin{array}{l}\text { Calculation } \\
\text { methodology } \\
\text { indicator }\end{array}$ & $\begin{array}{l}\text { Data collection methodology for } \\
\text { calculating the Standard indicator }\end{array}$ \\
\hline 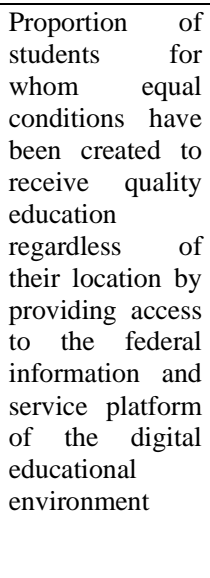 & $\%$ & 100 & $\begin{array}{l}\text { The proportion of } \\
\text { students for whom } \\
\text { there are equal } \\
\text { conditions for } \\
\text { receiving quality } \\
\text { education, regardless } \\
\text { of their location, by } \\
\text { providing access to the } \\
\text { federal information } \\
\text { and service platform of } \\
\text { the digital educational } \\
\text { environment is the } \\
\text { ratio of the number of } \\
\text { students who have } \\
\text { access to the DES with } \\
\text { the total number of } \\
\text { students multiplied by } \\
100 \text {. }\end{array}$ & $\begin{array}{l}\text { Data for the calculation of the indicator } \\
\text { should be obtained on the basis of } \\
\text { federal statistical observation forms № } \\
\text { OO-2 «Information about the material } \\
\text { and technical and information base, } \\
\text { financial and economic activity of the } \\
\text { general educational organization» } \\
\text { (Rosstat Order: on approval of the } \\
\text { form from 01.11.2019 № } 648 \text { (On } \\
\text { amendments (if any) from } 05.12 .2019 \\
\text { № 744), N SPO-2 «Information about } \\
\text { the material and technical and } \\
\text { information base, financial and } \\
\text { economic activity of the professional } \\
\text { educational organization», № OO-1 } \\
\text { «Information about the organization } \\
\text { that is preparing a professional } \\
\text { educational organization». }\end{array}$ \\
\hline
\end{tabular}




\section{Findings}

The using of this methodology will make it possible to create a standard of quality of life for the rural population, which will take into account the differences in spatial, territorial and social living conditions in different rural settlements, but at the same time its use will reduce the differentiation of the level and quality of life of urban and rural residents. The proposed methodology for developing a standard of quality of life in rural areas, makes it possible to establish the main areas, to identify the optimal list of services that ensure a high level and quality of life, as well as a list of indicators and their minimum acceptable values.

\section{References}

1. D.A. Loginova, A.S. Strokov, Issues of state and municipal management. Institutional Issues of Sustainable Development of Rural Areas of Russia. 2, 115-140, (2019)

2. L.Y. Piterskaya, T.G. Gurnovich, G.A. Baum, S.D. Fetisov. Lecture Notes in Networks and Systems. A systemic approach to the development of the theory of economic interaction of the institution of farming and a socially-oriented environment of a new type. 129, 866-874, (2020)

3. T.G. Gurnovich, L.V. Agarkova, V.A. Zhukova, A.F. Dolgopolova. Revista Turismo Estudos and Práticas. Development of innovative regional cluster of the regional aic on the basis of network simulation. 52, 5, (2020)

4. L.N. Usenko, A.M. Usenko, T.N. Uryadova, T.A. Bashkatova, S.V. Belyaeva. Espacios. Monitoring methodology for socio-economic development of a region (through the example of the south of Russia regions). 38, 24, (2017) 